\title{
Familial liability to schizophrenia and premorbid
} adjustment

\author{
MURIEL WALSHE, MARK TAYLOR, KATJA SCHULZE, ELVIRA BR AMON, \\ SOPHIA FRANGOU, DANIEL STAHL, EUGENIA KRAVARITI, EILEEN DALY, \\ PAUL FEARON, ROBIN M. MURRAY and COLM MCDONALD
}

\begin{abstract}
Summary We assessed premorbid functioning during childhood and adolescence in 50 people with schizophrenia from multiply affected families, 39 of their unaffected siblings, 69 people with schizophrenia with no family history of psychosis, 67 of their unaffected siblings and 83 controls. People with schizophrenia had poorer premorbid social and academic adjustment and exhibited a decline between childhood and adolescence compared with controls. Unaffected siblings from multiply affected families also had poor academic functioning in adolescence, with a decline between childhood and adolescence.This may represent a familial (presumed genetic) effect.
\end{abstract}

Declaration of interest None. E.B. and C.M. supported by the Wellcome Trust.

Cognitive and social deficits pre-date the onset of schizophrenia (Isohanni et al, 2005; Cannon et al, 2006) but it is unclear whether they reflect genetic liability. We examined the early social and academic functioning of individuals from the Maudsley Family Study to determine whether premorbid impairments in these functional domains are related to familial liability for schizophrenia. We hypothesised that individuals with a higher presumed genetic liability (i.e. those from multiply affected families) would display more prominent social and academic impairment than their counterparts from non-affected families.

\section{METHODS}

The recruitment and clinical assessments of the sample are described elsewhere
(McDonald et al, 2006). Briefly, multiply affected families were defined as having two or more first- and/or second-degree relatives with schizophrenia or another psychotic disorder, and singly affected families were those in which the index individual had no known family history of psychosis as far as their third-degree relatives. None of the control sample had a personal or family history of psychotic illness. All participants were White/Caucasian, aged 18-50 years and gave informed consent for their mother to be interviewed. The study had ethics approval.

Fifty people with 'familial' schizophrenia (37 male, 13 female; mean age 32 years, s.d.=6.1), 39 of their unaffected siblings (14 male, 25 female; mean age 34 years, s.d.=7.8), 69 people with 'non-familial' (52 male, 17 female; mean age 31 years, s.d.=6.4), 67 of their unaffected siblings (34 male, 33 female; mean age 35 , s.d.=7.6) and 83 controls (42 male, 41 female; mean age 31 years, s.d.=7.1) were recruited. Patients fulfilled DSM-IV (American Psychiatric Association, 1994) criteria for schizophrenia $(n=112)$, schizoaffective disorder $(n=6)$ or psychotic disorder 'not otherwise specified' $(n=1)$. Eleven (2 'non-familial' and 9 'familial') unaffected siblings had had an earlier DSM-IV Axis I non-psychotic psychiatric disorder, predominantly major depressive disorder.

A modified Premorbid Social Adjustment (PSA) scale (Cannon-Spoor et al, 1982) was used to examine childhood and adolescent functioning (Foerster et al, 1991; Hollis, 2003). The PSA scale assessed five areas (socialisation, peer relations, academic achievement, school adaptation and hobbies) over two consecutive time periods: 5-11 years (childhood) and 1216 years (adolescence). The PSA scale was then simplified into two categories: social adjustment (socialisation, peer relations and hobbies); and academic adjustment (academic achievement and school adaptation) (Allen et al, 2005). Higher scores indicated poorer functioning. Any developmental deterioration was calculated as a 'change score' by subtracting childhood adjustment from adolescent adjustment.

The scale was administered to the mothers by face-to-face interview $(64 \%)$ or using a self-report questionnaire $(36 \%)$. Reliability was established by asking 21 mothers who had completed face-to-face interviews to complete a self-report version of the PSA scale at a later time (on average 4 years). The scores for both time-points were highly consistent (correlation coefficient $=0.80$ ).

Multivariate analysis was carried out using STATA version 9.0 with clustered robust standard errors to account for the non-independence of individuals within families and for possible violations of normality and equal variance assumptions. Multiple linear regression was used to compare premorbid adjustment and change scores (dependent variables) of each patient and sibling group (independent variables) with the control group, controlling for age and gender. Scores were log-transformed to normalise the distributions. All tests were two-tailed using a 0.05 level of significance.

\section{RESULTS}

The groups did not significantly differ in measures of parental social class $\left(\chi^{2}=3.5\right.$, d.f. $=2, \quad P=0.71)$ or sibship size $(F(2$, $150)=0.4, P=0.65)$ but there were significant group differences for age $(F(4$, $151)=2.8, P=0.03)$ and gender $\left(\chi^{2}=22.2\right.$, d.f. $=4, P=0.002)$, which were controlled for in subsequent analyses. Siblings of people with non-familial psychosis were older than the control group and there was an excess of males in both patient groups.

Premorbid function scores are presented in Table 1. Compared with controls, both groups with schizophrenia had significantly worse social and academic function in childhood and adolescence, both of which deteriorated over time. The deterioration in social functioning only reached statistical significance for people with 'familial' schizophrenia. In a post hoc analysis directly comparing 'familial' and 'non-familial' schizophrenia, no significant difference was found in either premorbid social functioning or deterioration over time.

Neither unaffected sibling group differed significantly from controls in their social functioning during childhood or 
adolescence (Table 1). However, siblings of people with familial schizophrenia demonstrated significantly worse academic functioning than controls during adolescence, and had a deterioration in academic functioning between childhood and adolescence. Post hoc analysis demonstrated that siblings of people with familial schizophrenia also had a significantly greater decline in academic functioning when compared directly with 'non-familial' siblings $(B=-0.31, P=0.02,95 \%$ CI -0.56 to -0.06). Analyses were repeated excluding those 11 unaffected siblings with a history of non-psychotic psychiatric disorders but this made no difference to the results.

\section{DISCUSSION}

To our knowledge this is the first study demonstrating that unaffected siblings of people with familial schizophrenia have poor academic functioning during adolescence and deterioration in academic performance between childhood and adolescence compared with controls. This finding, coupled with its absence in siblings of people with non-familial schizophrenia suggests that academic problems may be related to genetic risk for schizophrenia. This is consistent with reports that adult relatives of people with schizophrenia underperform on cognitive tests compared with controls (Snitz et al, 2006).

This study has some methodological limitations. Separating families on the basis of family history of psychosis runs the risk that some families may be misclassified. People with non-familial schizophrenia may not represent illness phenocopies but multiply affected families are presumed more likely to carry a greater genetic susceptibility load than those families with

MURIEL WALSHE, BA, MARK TAYLOR, MRCPsych, KATJA SCHULZE, PhD, ELVIRA BRAMON, MD, SOPHIA FRANGOU, MD, DANIEL STAHL, PhD, EUGENIA KRAVARITI, PhD, EILEEN DALY, BSC, PAUL FEARON, MRCPsych, ROBIN M. MURRAY, FRCPsych, DSc and COLM McDONALD, MRCPsych, Division of Psychological Medicine, Institute of Psychiatry, London, UK

Correspondence: Dr Muriel Walshe, Division of Psychological Medicine, Institute of Psychiatry, De Crespigny Park, London SE5 8AF, UK. Email: m.walshe@iop.kcl.ac.uk

(First received 23 November 2006, final revision II April 2007, accepted 20 April 2007)

only one member affected. This is supported by studies which have found more prominent neurobiological deviations among unaffected relatives from more densely affected families (McDonald et al, 2006). It is also possible that recall bias was introduced by the retrospective assessment of behavioural functioning during childhood and adolescence, i.e. that mothers from multiply affected families were more likely to recall negative events in their children. However, maternal ratings across both patient groups (familial and non-familial) were very similar, arguing against such recall bias operating in multiply affected families.

Our finding that people who go on to develop schizophrenia have abnormal premorbid social and academic functioning in childhood and adolescence is in accordance with previous research (e.g. Isohanni $e t$ al, 2000), and other studies (Allen et al, 2005) have suggested that academic and social impairment accelerates as people who later develop schizophrenia move from childhood to adolescence.

\section{REFERENCES}

Allen, D. N., Frantom, L. V., Strauss, G. P., et al (2005) Differential patterns of premorbid academic and social deterioration in patients with schizophrenia. Schizophrenia Research, 75, 389-397.
American Psychiatric Association (1994) Diagnostic and Statistical Manual of Mental Disorders (4th edn) (DSM-IV). APA.

Cannon, M., Moffitt, T. E., Caspi, A., et al (2006) Neuropsychological performance at the age of 13 years and adult schizophreniform disorder. Prospective birth cohort study. British Journal of Psychiatry, 189, 463-464.

Cannon-Spoor, H., Potkin, S. G. \& Wyatt, R. J. (1982) Measurement of premorbid adjustment in chronic schizophrenia. Schizophrenia Bulletin, 8, 470-484.

Foerster, A., Lewis, S., Owen, M., et al (1991) Pre-morbid adjustment and personality in psychosis: Effects of sex and diagnosis. British Journal of Psychiatry I58, $171-176$.

Hollis, C. (2003) Developmental precursors of childand adolescent-onset schizophrenia and affective psychoses: diagnostic specificity and continuity with symptom dimensions. British Journal of Psychiatry, $\mathbf{1 8 2}$, 37-44.

Isohanni, M., Jones, P., Kemppainen, L., et al (2000) Childhood and adolescent predictors of schizophrenia in the Northern Finland 1966 Birth Cohort - A descriptive life-span model. European Archives of Psychiatry and Clinical Neuroscience, 250, 31I-319.

Isohanni, M., Lauronen, E., Moilanen, K., et al (2005) Predictors of schizophrenia. Evidence from the Northern Finland 1966 Birth Cohort and other sources. British Journal of Psychiatry, 187 (suppl. 48), s4-s7.

McDonald, C., Marshall, N., Sham, P., et al (2006) Regional brain morphometry in patients with schizophrenia or bipolar disorder and their unaffected relatives. American Journal of Psychiatry, 163, 478-487.

Snitz, B. E., MacDonald, A.W., III \& Carter, C. S. (2006) Cognitive deficits in unaffected first-degree relatives of schizophrenia patients: a meta-analytic review of putative endophenotypes. Schizophrenia Bulletin, 32, 179-194.

\begin{tabular}{|c|c|c|c|c|c|}
\hline & $\begin{array}{c}\text { Familial } \\
\text { schizophrenia } \\
(n=50)\end{array}$ & $\begin{array}{l}\text { Sibling - familial } \\
\text { schizophrenia } \\
(n=39)\end{array}$ & $\begin{array}{l}\text { Non-familial } \\
\text { schizophrenia } \\
\quad(n=69)\end{array}$ & $\begin{array}{l}\text { Sibling - non-familial } \\
\text { schizophrenia } \\
(n=67)\end{array}$ & $\begin{array}{l}\text { Controls } \\
(n=83)\end{array}$ \\
\hline \multicolumn{6}{|l|}{ PSA scale score: mean (s.d.) } \\
\hline Childhood social adjustment & $4.08(1.16)^{*}$ & $3.43(0.64)$ & $4.33(1.35)^{* * *}$ & $3.60(0.97)$ & $3.52(0.80)$ \\
\hline Adolescent social adjustment & $4.36(1.26)^{* * *}$ & $3.51(0.90)$ & $4.43(1.47)^{* * *}$ & $3.39(0.72)$ & $3.47(0.75)$ \\
\hline Change score for social adjustment & $0.28(0.73)^{*}$ & $0.05(0.70)$ & $0.10(0.99)$ & $-0.21(0.69)$ & $-0.05(0.62)$ \\
\hline Childhood academic adjustment & $3.08(1.10)^{* *}$ & $2.51(0.68)$ & $3.07(1.14)^{* * *}$ & $2.58(0.86)$ & $2.36(0.58)$ \\
\hline Adolescent academic adjustment & $3.46(1.42)^{* * *}$ & $2.84(0.96)^{* *}$ & $3.49(1.32)^{* * *}$ & $2.60(0.87)$ & $2.4 I(0.66)$ \\
\hline Change score for academic adjustment & $0.38(0.97)^{*}$ & $0.33(0.74)^{* *}$ & $0.42(0.99)^{* *}$ & $0.01(0.7 I)$ & $0.04(0.44)$ \\
\hline
\end{tabular}

$* P<0.05, * * P<0.01, * * * P<0.001 v$. controls in linear regression analysis. 